\title{
Social norms, attitudes and access to modern contraception for adolescent girls in six districts in Uganda
}

\author{
Paul Bukuluki ${ }^{*}$, Peter Kisaakye ${ }^{2}$, Maxime Houinato ${ }^{3}$, Adekemi Ndieli $^{3}$, Evelyn Letiyo ${ }^{3}$ and Dan Bazira ${ }^{3}$
}

\begin{abstract}
Background: Social norms continue to be entrenched in Uganda. Understanding social norms helps to uncover the underlying drivers that influence attitudes and behavior towards contraceptive access and use. This study therefore seeks to investigate the factors that influence the social norm - access to contraception by adolescent girls - in six districts in Uganda.
\end{abstract}

Data and methods:: Using data from a community cross-sectional survey in six districts (Amudat, Kaberamaido, Kasese, Moroto, Tororo and Pader) in Uganda, a binary logistic regression model was fitted to examine the variation in individual beliefs and socio-economic and demographic factors on 'allowing adolescent girls to access contraception in a community' - we refer to as a social norm.

Results: Results demonstrate that a higher proportion of respondents hold social norms that inhibit adolescent girls from accessing contraception in the community. After controlling for all variables, the likelihood for adolescent girls to be allowed access to contraception in the community was higher among respondents living in Kaberamaido $(\mathrm{OR}=2.58 ; 95 \% \mathrm{Cl}=1.23-5.39)$, Kasese $(\mathrm{OR}=2.62 ; 95 \% \mathrm{Cl}=1.25-5.47)$, Pader $(\mathrm{OR}=4.35 ; 95 \% \mathrm{Cl}=2.15-$ 8.79) and Tororo $(\mathrm{OR}=9.44 ; 95 \% \mathrm{Cl}=4.59-19.37)$, those aged 30-34 years likely $(\mathrm{OR}=1.73 ; 95 \% \mathrm{Cl}=1.03-2.91)$. However, the likelihood for respondents living in Moroto to agree that adolescent girls are allowed to access contraception was lower $(\mathrm{OR}=0.27 ; 95 \% \mathrm{Cl}=0.11-0.68)$ compared to respondents living in Amudat. Respondents who were not formally employed $(\mathrm{OR}=0.63 ; 95 \% \mathrm{Cl}=0.43-0.91)$, and those who agreed that withdrawal prevents pregnancy $(\mathrm{OR}=0.45 ; 95 \% \mathrm{Cl}=0.35-0.57)$ were less likely to agree that adolescent girls are allowed to access contraception in the community. Respondents who agreed that a girl who is sexually active can use contraception to prevent unwanted pregnancy $(\mathrm{OR}=1.84 ; 95 \% \mathrm{Cl}=1.33-2.53)$, unmarried women or girls should have access to contraception $(\mathrm{OR}=2.15 ; 95 \% \mathrm{Cl}=1.61-2.88)$, married women or girls should have access to contraception $(\mathrm{OR}=$ $1.55 ; 95 \% \mathrm{Cl}=0.99-2.39)$ and women know where to obtain contraception for prevention against pregnancy $(\mathrm{OR}=$ $2.35 ; 95 \% \mathrm{Cl}=1.19-4.65)$ were more likely to agree that adolescent girls are allowed to access contraception.

Conclusions: The findings underscore the need for context specific ASRH programs that take into account the differences in attitudes and social norms that affect access and use of contraception by adolescents.

Keywords: Social norms, Attitudes, Access and Use of Contraception, Adolescents, Uganda

* Correspondence: pbukuluki@gmail.com
${ }^{1}$ School of Social Sciences, Makerere University, Kampala, Uganda
Full list of author information is available at the end of the article

(c) The Author(s). 2021 Open Access This article is licensed under a Creative Commons Attribution 4.0 International License, which permits use, sharing, adaptation, distribution and reproduction in any medium or format, as long as you give appropriate credit to the original author(s) and the source, provide a link to the Creative Commons licence, and indicate if changes were made. The images or other third party material in this article are included in the article's Creative Commons licence, unless indicated otherwise in a credit line to the material. If material is not included in the article's Creative Commons licence and your intended use is not permitted by statutory regulation or exceeds the permitted use, you will need to obtain permission directly from the copyright holder. To view a copy of this licence, visit http://creativecommons.org/licenses/by/4.0/ The Creative Commons Public Domain Dedication waiver (http://creativecommons.org/publicdomain/zero/1.0/) applies to the data made available in this article, unless otherwise stated in a credit line to the data. 


\section{Introduction}

Several scholars have made an attempt to define and explain the concept of social norms. Most of the definitions lean towards their academic disciplines. Some scholars especially social scientists have argued that social norms are context-dependent rules of what is perceived as obligatory, appropriate, and acceptable behaviour shared by people in the same group, community or society $[1-3]$.

In this paper we lean more towards the sociological explanation of social norms that conceptualizes social norms as customary or unwritten rules that govern people's behavior in a community, that are enforced by relevant reference groups [5-7]. Social norms can be classified under three main perspectives: (1) Social norms as behavioral regularities - which result from repeating behaviors [8, 9]. (2) Pluralistic ignorance where individuals think that their personal beliefs, ideas or feelings are different from others but their public behavior should be the same [10-12] and (3) Social norms as social beliefs - governed by the behavior of other people in a community $[13,14]$.

Social norms have also been categorized into descriptive norms and injunctive norms [15]. Descriptive norms are conceptualized to refer to one's belief about what others typically do in a given situation while injunctive norms are one's belief about what actions other people approve and disapprove [15]. More recent publications by Ben Cislaghi and Lori Heise have cautioned practitioners to take into consideration what they call the "eight learnings" that practitioners should reflect upon as they plan to integrate a social norms perspective in their interventions [16]. These learnings include: Social norms and attitudes are different; Social norms and attitudes can coincide; Protective norms can offer important resources for achieving effective social improvement in people's health-related practices; Harmful practices are sustained by a matrix of factors that need to be understood in their interactions;

The prevalence of a norm is not necessarily a sign of its strength; Social norms can exert both direct and indirect influence; Publicizing the prevalence of a harmful practice can make things worse; and People-led social norm change is both the right and the smart thing to do [16]. These learnings underscore the complexity of the interaction between social norms and other structural and institutional factors that regulate behaviour especially sexual and reproductive health practices in different contexts. They also point to the need to appreciate the notion and reality that some social norms can be harmful while others are not $[13,16]$ underscoring the need to identify positive cultural resources that can serve as building blocks for promoting sexual and reproductive health [16]. Social norms can aid in understanding the reproductive health of adolescents or young girls in developing countries [6], but social norms also influence someone's attitudes and behavior [17]. For example, social norms can influence whether and how people can access contraception. This paper seeks to examine the variation in terms of individual beliefs and socioeconomic and demographic factors among respondents in six districts in Uganda on 'allowing adolescent girls to access contraception in a community' - we refer to as a social norm. In this paper, we refer to adolescent girls as girls in the age group 10-19 years [18]. This paper uses the terms 'contraception' and 'family planning' interchangeably to mean the same thing. Using the definition from the 'dictionary of demography', family planning refers to any attempt to control the number and spacing of children [19].

Adolescents constitute the largest proportion of the world's population [20]. Girls below the age of 18 years are a critical age group that needs to be supported along their life trajectories [20-23]. However, adolescent girls tend to be disproportionately affected by the gendered social norms more than boys [24-28]. Social norms have been observed to impede access and use of modern contraception particularly among adolescent girls [22] As a result adolescent girls face a problem meeting their sexual and reproductive health needs [21]. For example, some social norms prevent adolescent girls from making decisive and independent decisions regarding their reproductive health such as access or the use of contraception [29]. The problem is compounded with early initiation of sexual intercourse [30]. Such practices would make adolescent girls get unwanted pregnancies [31], sexually transmitted diseases [32] or early marriages [33] that would have been averted, if they had the freedom to make independent choices about the use of contraception [30, 34, 35]. For example, in Ethiopia, social norms force adolescent girls to enter into early marriages to preserve their virginity, but also prevent out-ofmarriage births [21]. In Uganda, about half (49\%) of girls get married by the age of 18 years [36].

Recent studies [4, 24] have emphasized that social norms can have an effect on adolescents and that ultimately shapes how adolescents manage their reproductive health spheres later in life. That is, social norms can have an effect on the way adolescent girls make sexual and reproductive health choices. This is because social norms are adopted and internalized when people are still young [21].

While there is a large body of evidence on social norms or access and use of contraception, little is known about the effect of social norms on reproductive health, such as access and use of contraception in Uganda [4, $22,24]$. Yet, understanding the sociocultural context can help in designing strategic and positive interventions 
aimed at improving sexual and reproductive health behavior of adolescent girls [21, 25]. For example, some sociocultural contexts do not permit free discussions related to sexual and reproductive health with young people [30, 37-39]. Moreover, most sexual and reproductive health interventions tend to focus on older women while neglecting adolescent girls that are dealing with emerging issues about sexual and reproductive health such as sexuality, fertility or puberty [40].

This study therefore seeks to investigate the factors that influence the social norm - access to contraception by adolescent girls - in six districts in Uganda. We answer this by examining the socio-economic and demographic as well as individual beliefs/attitudes that influence allowing adolescent girls to have access to contraception. We expect that individuals with positive attitudes or beliefs about sexual and reproductive health behavior are more likely to agree that adolescent girls are allowed to access contraception in their community. The results in this study can inform policies that can be scaled-up or reformulated to challenge the status-quo which can help avert early marriages, unwanted pregnancies among young people. Such policies can incorporate improving young girls' agency and ability to make informed sexual and reproductive health goals [21]. Ultimately, the results in this study can help in the design of norm-focused interventions rather than individual-focused interventions in promoting better sexual and reproductive health behavior among adolescents $[16,23,41]$.

\section{Context}

The six districts in the study are; Amudat, Kaberamaido, Kasese, Moroto, Tororo and Pader. Three of the districts (Amudat, Moroto, and Pader) are located in the northern region, two districts (Kaberamaido and Tororo) in the eastern region and Kasese district in the western region. Amudat and Moroto are located in Karamoja subregion - which is one of the least developed regions in Uganda [42, 43]. Agriculture forms the main economic activity in the study districts [44]. Social norms and patriarchy systems continue to be entrenched in the study districts - and often prohibit girls or women from making independent life choices $[45,46]$.

According to the 2014 National Population and Housing Census, Amudat district has a total population of about 105,769 people. The total population of adolescents aged 0-17 years is 61,299 people. The total number of ever married females aged 10-19 years is 1,614 [47]. Moroto district has a total population of about 103,432 people. The total population of adolescents aged $0-17$ years is 54,975 people. The total number of ever married females aged 10-19 years is 1,933 [48]. Pader district has a total population of about 178,004 people. The total population of adolescents aged $0-17$ years is
102,812 people. The total number of ever married females aged 10-19 years is 3,569 [49]. Kaberamaido district has a total population of about 215,026 people. The total population of adolescents aged $0-17$ years is 126,093 people. The total number of ever married females aged 10-19 years is 3,694 [50]. Tororo district has a total population of about 517,080 people. The total population of adolescents aged 0-17 years is 291,043 people. The total number of ever married females aged $10-19$ years is 10,155 [51], and Kasese district has a total population of about 694,987 people. The total population of adolescents aged $0-17$ years is 385,664 people. The total number of married females aged 10-19 years is 12,665 [52].

\section{Data and methods \\ Source of data}

All methods were carried out in accordance with relevant guidelines and regulations. The data used in this study come from a community cross-sectional survey. The survey aimed at collecting data that can be used to assess social norms and sexual and reproductive health rights (SRHRs), violence against women and girls (VAWG) and harmful practices (HP).

\section{Study sites and population}

Data collection took place in six districts of Uganda (Amudat, Kaberamaido, Kasese, Moroto, Tororo and Pader) where the EU Spotlight Initiative to eliminate violence against women and girls is implemented [53, 54].

Figure 1 shows the location of the districts in the study. Amudat district is located in the Karamoja subregion in the northern region, Kaberamaido in the Teso sub-region in the eastern region, Kasese in Rwenzururu sub-region in the western region, Moroto in Karamoja sub-region in the northern region, Tororo in the Elgon sub-region in the eastern region, and Pader in Acholi sub-region in the northern region [55].

\section{Sampling}

A list of locations within each district was developed together with the community leaders. The community survey was based on a stratified two-stage cluster design, with districts as study domains. In the first stage, a simple random sample of ten villages was taken using probability proportional to size (approximate number of households) sampling in each district. In the second stage, a list of locations within the selected villages was classified into small and large areas or routes or path junctions of traffic. A simple random sample of 3-5 small locations and 2-3 large locations were chosen. Finally, a systematic random sampling approach was used to recruit respondents by recruiting every third person 


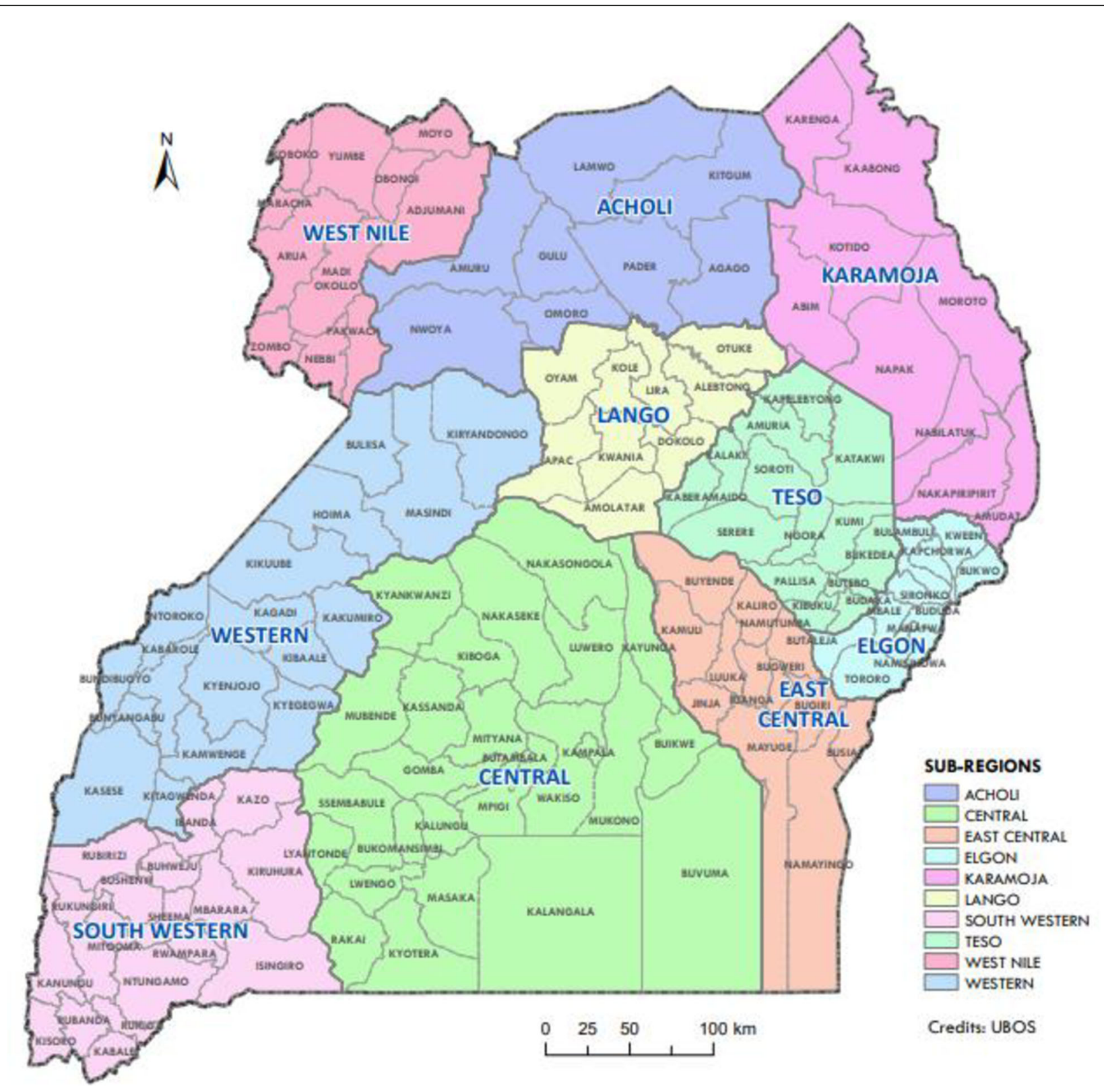

Fig. 1 A map of Uganda showing the location of the districts in the study

wearing a certain color of clothes. Using the formula of simple random sampling with proportions, $\mathrm{p}=0.05495$, $\mathrm{q}=0.94505, \quad \mathrm{z}=2.58$, margin of error $=+/-1 \%$ at $99 \%$ level of significance, we estimated a sample of 3456 respondents. The response rate was $99 \%$ since the actual sample size was 3427 individuals.

\section{Data collection}

Data collection took place in August-September 2019 by a team of four well trained research assistants per district (two females and two males). Interviews were done in a private setting, and responses were electronically recorded using a mobile tablet programmed with a quantitative survey tool. Given the sensitivity of some of the questions included in the survey, female interviewers were required to interview only female respondents while male interviewers were required to interview only male respondents. A pre-test was done prior to the actual data collection exercise. This was aimed to test the validity and reliability of the questionnaire and lessons learned during the pre-test were incorporated in the final revision of the quantitative questionnaire. 


\section{Variables}

The socio-economic and demographic variables that were included in the study are sex (female or male), age in single years, current marital status (single, currently married, widowed or separated or divorced), level of education (no education, primary, secondary, vocational or university), religion (Catholic, Protestant, Born again, Moslem, SDA, Traditional) and formal employment in the last three months preceding the survey (no or yes).

The study also collected information on people's attitudes/ beliefs about access and use of contraception: Consistent use of the condom prevents pregnancy, It is not easy for women below 20 years to get pregnant, Belief that withdrawal prevents pregnancy, Women or girls have a right to access family planning methods, A girl who is sexually active can use contraception to prevent unwanted pregnancy, Unmarried women or girls should have access to contraception, Married women or girls should have access to contraception, Women know where to obtain contraception for prevention against pregnancy, Women who carry condoms are promiscuous, and It is not good for girls to know about sexual matters because they will get spoilt. Responses to each of these attitudinal questions were disagree or agree.

Respondents were asked whether adolescent girls are allowed to access contraception in the community. Responses to this question were either a yes or no. This question was used to measure the social norm that influences access and use of contraception in communities as the outcome variable.

\section{Data analysis}

The Stata statistical software was used to analyze the data [56]. Results were presented at the univariate, bivariate and multivariable level of analyses. Frequencies were estimated at the univariate level of analysis to show the distribution of respondents. A Chi-square test was estimated at the bivariate level to measure the relationship between selected variables and access to contraception by adolescent girls in the community. At the multivariable level of analysis, a binary logistic regression model was fitted to examine the factors that are associated with access to contraception by adolescent girls in the community.

\section{Ethical considerations}

Permission to conduct the study was granted by the School of Social Sciences at Makerere University and Uganda National Council for Science and Technology (SS4951). All respondents who participated in the survey provided verbal informed consent before the interview could start. Respondents were assured of utmost safety, confidentiality, voluntary participation and withdraw from the survey without any penalty.

\section{Results}

Characteristics of the respondents

Table 1 shows the distribution of respondents in the survey by socio-economic and demographic factors. About two-thirds $(66 \%)$ of respondents were females. Four out of every five respondents $(80 \%)$ were currently married at the time of the survey. About 4 out of every 10 respondents (43\%) had primary education. Half (50\%) of the respondents belonged to the Catholic religious faith. Table 1 shows that about five out of every six respondents $(85 \%)$ were not formally employed in the last three months preceding the survey.

Table 2 shows the distribution of respondents by attitudes about access and use of contraception. The majority agreed that consistent use of the condom prevents pregnancy $(80 \%)$, women and girls have a right to access family planning methods (60\%), a girl who is sexually active can use contraception to prevent unwanted pregnancy $(60 \%)$, married women or girls should have access to contraception (73\%), women know where to obtain contraception for prevention against pregnancy (84\%), women who carry condoms are promiscuous (75\%) and it is not good for girls to know about sexual matters because they will get spoilt $(70 \%)$. Table 2 also shows that about half $(50 \%)$ of the respondents agreed that withdrawal prevents pregnancy and unmarried women or girls should have access to contraception.

\section{Relationship between selected factors and access to contraception by adolescent girls in community}

Table 3 shows that respondents were significantly different by access to contraception by adolescent girls in the community by age of the respondent $(p<0.01)$, current marital status $(p<0.01)$, level of education $(p<0.001)$, and religion $(p<0.001)$. Overall, the results shown in Table 3 indicate that the majority of respondents (73\%) agreed to the social norm that adolescent girls are not allowed to access contraception. However, the proportion of currently married or ever married (widowed, divorced, separated) respondents who stated that adolescent girls are not allowed to access contraception is higher than single respondents. Results indicate that respondents were significantly different by access to contraception by adolescent girls in the community by study district $(p<0.001)$. A higher proportion of respondents who reported that adolescent girls are not allowed access to contraception is observed in all countries but Tororo.

Table 4 shows that respondents were significantly different by access to contraception by adolescent girls in the community by all attitudes but it is not easy for women below 20 years to get pregnant'. However, the 
Table 1 Distribution of respondents by socio-economic and demographic factors

\begin{tabular}{|c|c|c|}
\hline Social economic and demographic variables & Number & Percent \\
\hline \multicolumn{3}{|l|}{ Sex } \\
\hline Male & 1159 & 33.8 \\
\hline Female & 2268 & 66.2 \\
\hline \multicolumn{3}{|l|}{ Age of respondent } \\
\hline $15-19$ & 349 & 10.2 \\
\hline $20-24$ & 576 & 16.8 \\
\hline $25-29$ & 674 & 19.7 \\
\hline $30-34$ & 558 & 16.3 \\
\hline $35-39$ & 462 & 13.5 \\
\hline $40-44$ & 349 & 10.2 \\
\hline $45+$ & 459 & 13.4 \\
\hline \multicolumn{3}{|l|}{ Current marital status } \\
\hline Single & 466 & 13.6 \\
\hline Married & 2740 & 79.9 \\
\hline Widowed/ Divorced/ Separated & 221 & 6.5 \\
\hline \multicolumn{3}{|l|}{ Education } \\
\hline No education & 1005 & 29.3 \\
\hline Primary & 1491 & 43.5 \\
\hline Secondary & 707 & 20.6 \\
\hline Vocational/ University & 224 & 6.5 \\
\hline \multicolumn{3}{|l|}{ Religion } \\
\hline Catholic & 1735 & 50.6 \\
\hline Born again & 556 & 16.2 \\
\hline Protestant & 994 & 29 \\
\hline Traditional & 51 & 1.5 \\
\hline Moslem & 54 & 1.6 \\
\hline SDA & 37 & 1.1 \\
\hline \multicolumn{3}{|l|}{ Formally employed in last 3 months } \\
\hline No & 2904 & 84.7 \\
\hline Yes & 523 & 15.3 \\
\hline \multicolumn{3}{|l|}{ Study district } \\
\hline Amudat & 566 & 16.5 \\
\hline Kaberamaido & 571 & 16.7 \\
\hline Kasese & 583 & 17.0 \\
\hline Moroto & 557 & 16.2 \\
\hline Pader & 576 & 16.8 \\
\hline Tororo & 574 & 16.8 \\
\hline Total & 3427 & 100 \\
\hline
\end{tabular}

Note: SDA = Seventh Day Adventist. Missing cases are not shown. Figures may not add up to $100 \%$ due to rounding errors
Table 2 Distribution of respondents by beliefs about access and use of contraception

\begin{tabular}{|c|c|c|}
\hline Beliefs about access and use of contraception & Number & Percent \\
\hline \multicolumn{3}{|l|}{ Consistent use of the condom prevents pregnancy } \\
\hline Disagree & 694 & 20.3 \\
\hline Agree & 2733 & 79.8 \\
\hline \multicolumn{3}{|l|}{$\begin{array}{l}\text { It is not easy for women below } 20 \text { years to get } \\
\text { pregnant }\end{array}$} \\
\hline Disagree & 2900 & 84.6 \\
\hline Agree & 527 & 15.4 \\
\hline \multicolumn{3}{|l|}{ Belief that withdrawal prevents pregnancy } \\
\hline Disagree & 1155 & 50.9 \\
\hline Agree & 1113 & 49.1 \\
\hline \multicolumn{3}{|l|}{$\begin{array}{l}\text { Women or girls have a right to access family } \\
\text { planning methods }\end{array}$} \\
\hline Disagree & 1359 & 39.7 \\
\hline Agree & 2068 & 60.3 \\
\hline \multicolumn{3}{|l|}{$\begin{array}{l}\text { A girl who is sexually active can use contraception } \\
\text { to prevent unwanted pregnancy }\end{array}$} \\
\hline Disagree & 1357 & 39.6 \\
\hline Agree & 2070 & 60.4 \\
\hline \multicolumn{3}{|l|}{$\begin{array}{l}\text { Unmarried women or girls should have access to } \\
\text { contraception }\end{array}$} \\
\hline Disagree & 1768 & 51.6 \\
\hline Agree & 1659 & 48.4 \\
\hline \multicolumn{3}{|l|}{$\begin{array}{l}\text { Married women or girls should have access to } \\
\text { contraception }\end{array}$} \\
\hline Disagree & 926 & 27.0 \\
\hline Agree & 2501 & 73.0 \\
\hline \multicolumn{3}{|l|}{$\begin{array}{l}\text { Women know where to obtain contraception for } \\
\text { prevention against pregnancy }\end{array}$} \\
\hline Disagree & 540 & 15.8 \\
\hline Agree & 2887 & 84.2 \\
\hline \multicolumn{3}{|l|}{ Women who carry condoms are promiscuous } \\
\hline Disagree & 832 & 24.5 \\
\hline Agree & 2563 & 75.5 \\
\hline \multicolumn{3}{|l|}{$\begin{array}{l}\text { It is not good for girls to know about sexual } \\
\text { matters because they will get spoilt }\end{array}$} \\
\hline Disagree & 1018 & 29.8 \\
\hline Agree & 2401 & 70.2 \\
\hline Total & 3427 & 100 \\
\hline
\end{tabular}

Note: Missing cases are not shown. Figures may not add up to $100 \%$ due to rounding errors

proportion of respondents that agreed that adolescent girls are not allowed to access contraception in the community by different attitudes such as 'consistent use of the condom prevents pregnancy' (69\%), 'women or girls have a right to access family planning methods' (63\%), 'a girl who is sexually active can use contraception to 
Table 3 Relationship between social-economic and demographic factors and access to contraception in the community

\begin{tabular}{|c|c|c|c|c|}
\hline \multirow{2}{*}{$\begin{array}{l}\text { Social economic and } \\
\text { demographic variables }\end{array}$} & \multicolumn{2}{|c|}{ Adolescent girls are allowed to access contraception in this community } & \multirow{2}{*}{$\begin{array}{l}\text { Chi-square } \\
\text { (P-value) }\end{array}$} & \multirow[t]{2}{*}{ Tota } \\
\hline & No & Yes & & \\
\hline Sex & & & $1.47(0.226)$ & \\
\hline Male & 72.2 & 27.8 & & 100 \\
\hline Female & 74.1 & 25.9 & & 100 \\
\hline Age of respondent & & & $16.98(0.009)^{* * *}$ & \\
\hline $15-19$ & 70.1 & 29.9 & & 100 \\
\hline $20-24$ & 70.0 & 30.0 & & 100 \\
\hline $25-29$ & 76.9 & 23.2 & & 100 \\
\hline $30-34$ & 73.3 & 26.7 & & 100 \\
\hline $35-39$ & 77.8 & 22.2 & & 100 \\
\hline $40-44$ & 74.7 & 25.3 & & 100 \\
\hline $45+$ & 70.0 & 30.0 & & 100 \\
\hline Current marital status & & & $14.13(0.001)^{* * *}$ & \\
\hline Single & 66.3 & 33.7 & & 100 \\
\hline Married & 74.5 & 25.5 & & 100 \\
\hline Widowed/ Divorced/ Separated & 75.0 & 25.0 & & 100 \\
\hline Education & & & $233.82(0.000)^{* * * *}$ & \\
\hline No education & 91.3 & 8.7 & & 100 \\
\hline Primary & 65.2 & 34.8 & & 100 \\
\hline Secondary & 66.3 & 33.7 & & 100 \\
\hline Vocational/ University & 71.0 & 29.0 & & 100 \\
\hline Religion & & & $57.29(0.000)^{* * * *}$ & \\
\hline Catholic & 69.5 & 30.5 & & 100 \\
\hline Born again & 80.8 & 19.2 & & 100 \\
\hline Protestant & 76.5 & 23.5 & & 100 \\
\hline Traditional & 93.9 & 6.1 & & 100 \\
\hline Moslem & 51.9 & 48.2 & & 100 \\
\hline SDA & 70.3 & 29.7 & & 100 \\
\hline Formally employed in last 3 months & & & $0.50(0.477)$ & \\
\hline No & 73.2 & 26.8 & & 100 \\
\hline Yes & 74.7 & 25.3 & & 100 \\
\hline Study district & & & $727.53(0.000)^{* * * *}$ & \\
\hline Amudat & 95.0 & 5.0 & & 100 \\
\hline Kaberamaido & 73.4 & 26.6 & & 100 \\
\hline Kasese & 79.1 & 20.9 & & 100 \\
\hline Moroto & 96.0 & 4.0 & & 100 \\
\hline Pader & 61.6 & 38.4 & & 100 \\
\hline Tororo & 36.6 & 63.4 & & 100 \\
\hline Total & 73.5 & 26.6 & & 100 \\
\hline
\end{tabular}

Note: ${ }^{* * *}=p<0.01 ;{ }^{* * *}=p<0.001$. SDA $=$ Seventh Day Adventist. Missing cases are not shown. Figures may not add up to $100 \%$ due to rounding errors

prevent unwanted pregnancy' (63\%), 'unmarried women or girls should have access to contraception' (57\%), 'married women or girls should have access to contraception' (67\%) and 'women know where to obtain contraception for prevention against pregnancy' (70\%) was lower than the proportion that disagreed. 
Table 4 Relationship between beliefs about access and use of contraception and access to contraception in the community

\begin{tabular}{|c|c|c|c|c|}
\hline \multirow[t]{2}{*}{ Beliefs about access and use of contraception } & \multicolumn{2}{|c|}{$\begin{array}{l}\text { Adolescent girls are allowed to } \\
\text { access contraception in this } \\
\text { community }\end{array}$} & \multirow[t]{2}{*}{$\begin{array}{l}\text { Chi-square ( } P \text { - } \\
\text { value) }\end{array}$} & \multirow[t]{2}{*}{ Tota } \\
\hline & No & Yes & & \\
\hline Consistent use of the condom prevents pregnancy & & & $126.61(0.000)^{* * * *}$ & \\
\hline Disagree & 90.4 & 9.6 & & 100 \\
\hline Agree & 69.2 & 30.8 & & 100 \\
\hline It is not easy for women below 20 years to get pregnant & & & $0.02(0.886)$ & \\
\hline Disagree & 73.5 & 26.5 & & 100 \\
\hline Agree & 73.2 & 26.8 & & 100 \\
\hline Belief that withdrawal prevents pregnancy & & & $5.75(0.016)^{* *}$ & \\
\hline Disagree & 71.9 & 28.1 & & 100 \\
\hline Agree & 76.4 & 23.7 & & 100 \\
\hline Women or girls have a right to access family planning methods & & & $298.25(0.000)^{* * * *}$ & \\
\hline Disagree & 89.6 & 10.4 & & 100 \\
\hline Agree & 62.9 & 37.1 & & 100 \\
\hline A girl who is sexually active can use contraception to prevent unwanted pregnancy & & & $296.94(0.000)^{* * * *}$ & \\
\hline Disagree & 89.6 & 10.4 & & 100 \\
\hline Agree & 62.9 & 37.1 & & 100 \\
\hline Unmarried women or girls should have access to contraception & & & $427.09(0.000)^{* * * *}$ & \\
\hline Disagree & 88.6 & 11.4 & & 100 \\
\hline Agree & 57.3 & 42.7 & & 100 \\
\hline Married women or girls should have access to contraception & & & $213.44(0.000)^{* * * *}$ & \\
\hline Disagree & 91.6 & 8.4 & & 100 \\
\hline Agree & 66.8 & 33.3 & & 100 \\
\hline Women know where to obtain contraception for prevention against pregnancy & & & $113.76(0.000)^{* * * *}$ & \\
\hline Disagree & 92.2 & 7.9 & & 100 \\
\hline Agree & 70.0 & 30.0 & & 100 \\
\hline Women who carry condoms are promiscuous & & & $31.34(0.000)^{* * * *}$ & \\
\hline Disagree & 65.9 & 34.1 & & 100 \\
\hline Agree & 75.8 & 24.2 & & 100 \\
\hline It is not good for girls to know about sexual matters because they will get spoilt & & & $48.74(0.000)^{* * * *}$ & \\
\hline Disagree & 65.3 & 34.7 & & 100 \\
\hline Agree & 76.8 & 23.2 & & 100 \\
\hline Total & 73.5 & 26.6 & & \\
\hline
\end{tabular}

\section{Factors associated with access to contraception by adolescent girls in the community}

The results shown in Fig. 2 depict estimates from Model 1 that controlled for only socio-economic and demographic factors that influence the social norm (access to contraception by adolescent girls in the community). Figure 2 shows that respondents aged 30-34 years $(\mathrm{OR}=$ $1.80 ; 95 \% \mathrm{CI}=1.20-2.69), \quad 35-39$ years $(\mathrm{OR}=1.59$; $95 \% \mathrm{CI}=1.04-2.45), 40-44$ years $(\mathrm{OR}=1.74 ; 95 \% \mathrm{CI}=$ $1.11-2.71)$ and 45 or more years $(\mathrm{OR}=1.58 ; 95 \% \mathrm{CI}=$
1.04-2.39) were more likely to agree that adolescent girls are allowed to access contraception in the community than respondents aged 15-19 years. Ever married (widowed, divorced, separated) $(\mathrm{OR}=0.61 ; 95 \% \mathrm{CI}=$ $0.38-0.96)$ respondents were less likely to agree that adolescent girls are allowed to access contraception in the community than single respondents.

Figure 2 shows that respondents with primary $(\mathrm{OR}=$ $2.03 ; 95 \% \mathrm{CI}=1.48-2.79)$, secondary $(\mathrm{OR}=1.67 ; 95 \% \mathrm{CI}=$ $1.17-2.39)$ or vocational/university $(\mathrm{OR}=1.94 ; 95 \% \mathrm{CI}=$ 


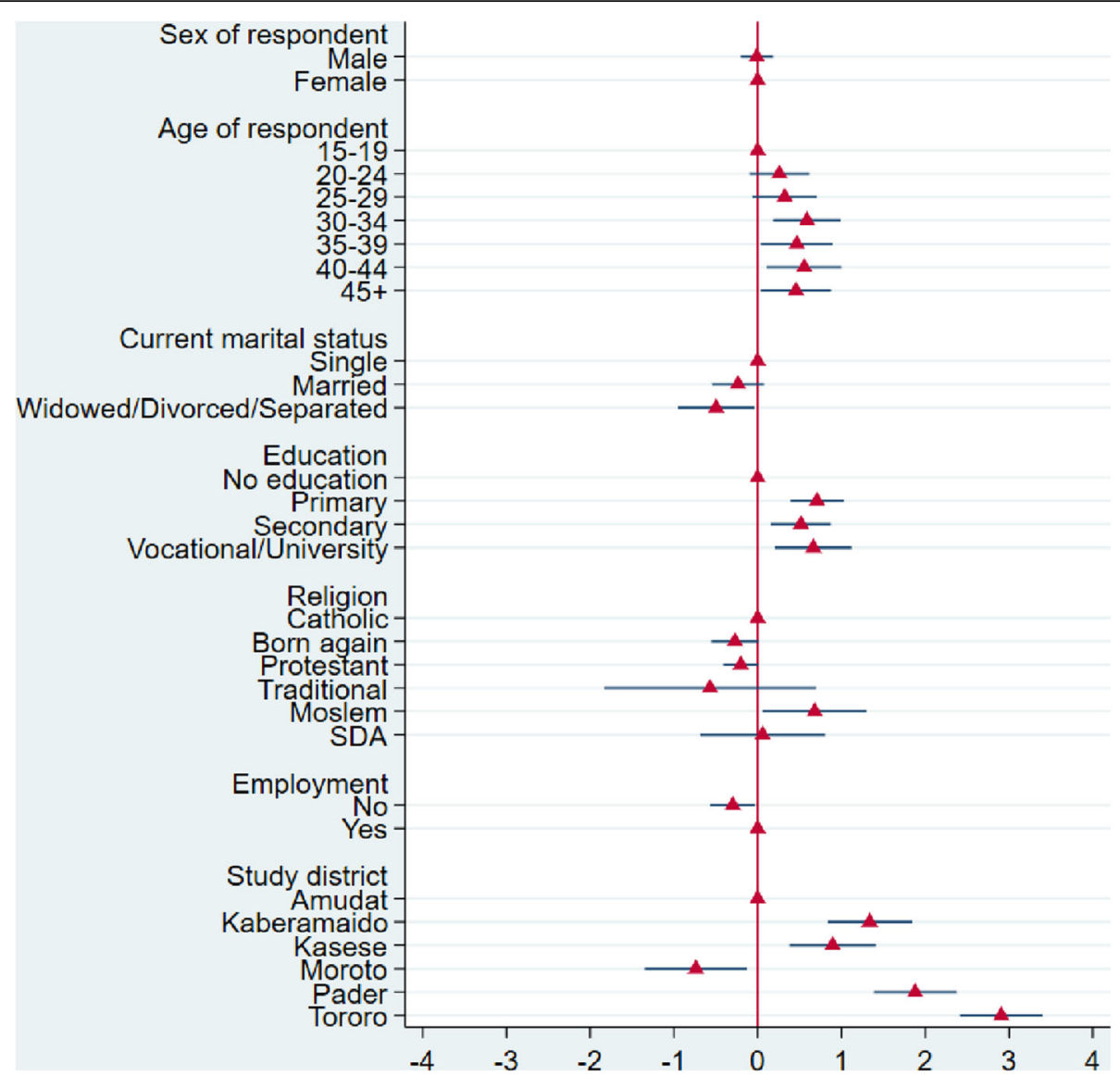

Fig. 2 Socio-economic and demographic factors associated with access to contraception by adolescent girls in a community (Model 1)

1.23-3.06) were more likely to state that adolescent girls are allowed to access contraception in the community than respondents with no education. Muslims $(\mathrm{OR}=1.97$; $95 \% \mathrm{CI}=1.06-3.66)$ were more likely to mention that adolescent girls in the community are allowed to access contraception than the Catholics. Respondents with no formal employment in the last three months preceding the survey were less likely $(\mathrm{OR}=0.74 ; 95 \% \mathrm{CI}=0.57-0.97)$ to mention that adolescent girls are allowed to access contraception in the community than their counterparts that were not formally employed. Respondents in Kaberamaido $(\mathrm{OR}=3.81 ; 95 \% \mathrm{CI}=2.30-6.31)$, Kasese $(\mathrm{OR}=$ $2.44 ; 95 \% \mathrm{CI}=1.46-4.09)$, Pader $(\mathrm{OR}=6.56 ; 95 \% \mathrm{CI}=$ 4.01-10.73) and Tororo $(\mathrm{OR}=18.29$; $95 \% \mathrm{CI}=11.17-$ 29.95) were more likely to mention that adolescent girls are allowed to access in the community contraception while respondents in Moroto $(\mathrm{OR}=0.48$; $95 \% \mathrm{CI}=0.26$ 0.88 ) were less likely to mention that adolescent girls are allowed to access contraception in the community compared to respondents in Amudat.

Figure 3 shows results from Model 2 that controlled for only individual attitudes. Respondents who agreed that consistent use of the condom prevents pregnancy $(\mathrm{OR}=$
2.26 ; $95 \% \mathrm{CI}=1.55-3.28$ ), a girl who is sexually active can use contraception to prevent unwanted pregnancy $(\mathrm{OR}=$ 2.01; $95 \% \mathrm{CI}=1.49-2.72$ ), unmarried women or girls should have access to contraception $(\mathrm{OR}=2.51 ; 95 \% \mathrm{CI}=$ 1.93-3.26), married women or girls should have access to contraception $\quad(\mathrm{OR}=1.89 ; \quad 95 \% \mathrm{CI}=1.25-2.88) \quad$ and women know where to obtain contraception for prevention against pregnancy $(\mathrm{OR}=2.39 ; 95 \% \mathrm{CI}=1.27-4.53)$ were more likely to agree that adolescent girls are allowed to access contraception in the community than respondents who disagreed to any of the beliefs.

The results in Fig. 3 show that respondents who agreed that is it not easy for women below 20 years to get pregnant $(\mathrm{OR}=0.68 ; 95 \% \mathrm{CI}=0.50-0.91)$, withdrawal prevents pregnancy $(\mathrm{OR}=0.47 ; 95 \% \mathrm{CI}=0.38$ 0.59 ) and it is not good for girls to know about sexual matters because they will get spoilt $(\mathrm{OR}=0.74 ; 95 \% \mathrm{CI}=$ 0.59-0.93) were less likely to agree that adolescent girls in the community are allowed to access contraception than their counterparts who disagreed to any of the attitudinal statements.

Table 5 shows results from the full model (Model 3) that controlled for all variables considered in this study. 


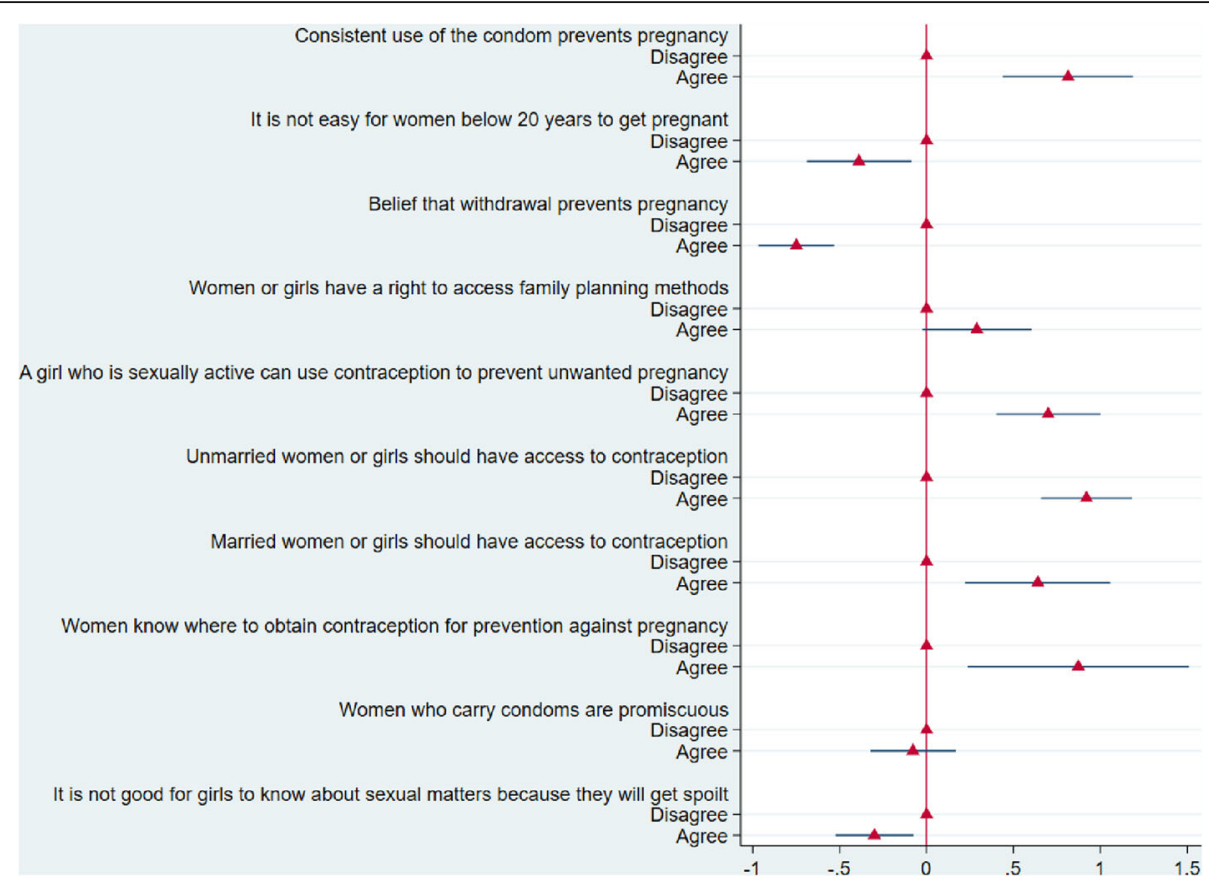

Fig. 3 Beliefs about access and use of contraception associated with access to contraception in a community (Model 2)

When all variables are considered, the results indicate that respondents aged $30-34$ years were more likely $(\mathrm{OR}=$ $1.73 ; 95 \% \mathrm{CI}=1.03-2.91)$ to agree that adolescent girls are allowed to access contraception in the community than respondents aged 15-19 years. Respondents who were not formally employed in the last three months preceding the survey $(\mathrm{OR}=0.63 ; 95 \% \mathrm{CI}=0.43-0.91)$ were less likely to agree that adolescent girls are allowed to access contraception in the community than respondents who were formally employed. The results in Table 5 show a similar pattern to the one in Fig. 3. That is, respondents who agreed that withdrawal prevents pregnancy $(\mathrm{OR}=0.45$; $95 \% \mathrm{CI}=0.35-0.57)$ were less likely to agree that adolescent girls are allowed to access contraception in the community than those that disagreed.

Respondents who agreed that a girl who is sexually active can use contraception to prevent unwanted pregnancy $(\mathrm{OR}=1.84 ; 95 \% \mathrm{CI}=1.33-2.53)$, unmarried women or girls should have access to contraception $(\mathrm{OR}=2.15 ; 95 \% \mathrm{CI}=1.61-2.88)$, married women or girls should have access to contraception $(\mathrm{OR}=1.55$; $95 \% \mathrm{CI}=0.99-2.39)$ and women know where to obtain contraception for prevention against pregnancy $(\mathrm{OR}=2.35 ; 95 \% \mathrm{CI}=1.19-4.65)$ were more likely to agree that adolescent girls are allowed to access contraception in the community than their counterparts who disagreed. The results in Table 5 show that the likelihood for adolescent girls to be allowed access to contraception in the community was higher in Kaberamaido $(\mathrm{OR}=2.58 ; 95 \% \mathrm{CI}=1.23-5.39)$, Kasese
$(\mathrm{OR}=2.62 ; \quad 95 \% \mathrm{CI}=1.25-5.47), \quad$ Pader $\quad(\mathrm{OR}=4.35$; $95 \% \mathrm{CI}=2.15-8.79)$ and Tororo $(\mathrm{OR}=9.44 ; 95 \% \mathrm{CI}=$ 4.59-19.37). However, the likelihood for respondents living in Moroto to agree that adolescent girls are allowed to access contraception was lower $(\mathrm{OR}=0.27$; $95 \% \mathrm{CI}=0.11-0.68)$ compared to respondents living in Amudat.

\section{Discussion}

This study demonstrates a relatively high proportion of respondents having negative attitudes in relation to access to contraceptive services for adolescents. This is in line with other studies that have generated similar results [21, 22, 29]. Similarly, other studies have shown that prevalent of negative attitudes towards women/girls carrying condoms, sexuality education for girls, and unmarried women or girls' access to contraception in low income settings [4, 22, 24].

Our study shows that it is not acceptable for adolescent girls in the community to access contraceptives This shows that this norm is widely shared in the communities in our study sites and this has implications for access to adolescent sexual and reproductive health services especially contraceptives [30, 37]. Further, given the significant differences in relation to this social norm-"girls are not allowed to access contraception in this community" by age, marital status, level of education and religion, programmes engaged in promoting SRHR particularly for adolescents must pay attention to differences in beliefs in the various age groups, among 
Table 5 Socio-economic, demographic factors, and beliefs about access and use of contraception associated with access to contraception in a community (Model 3)

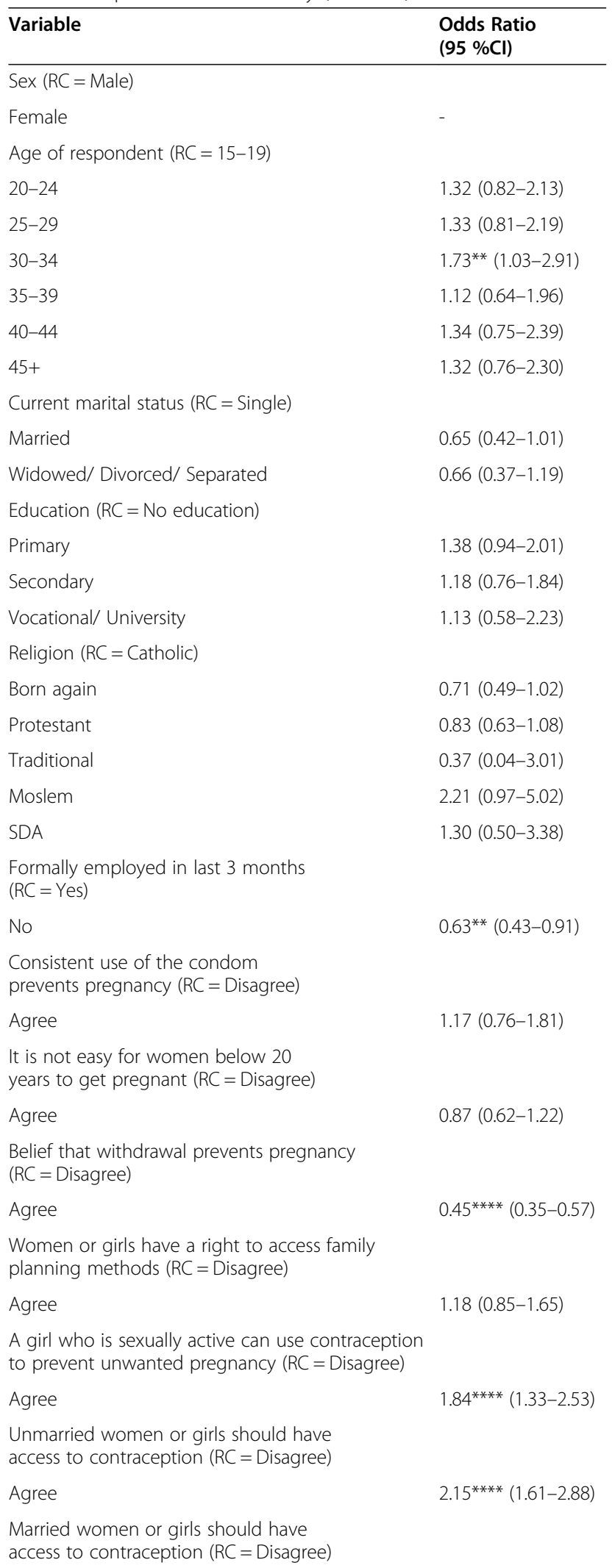

Table 5 Socio-economic, demographic factors, and beliefs about access and use of contraception associated with access to contraception in a community (Model 3) (Continued)

\begin{tabular}{ll}
\hline Variable & $\begin{array}{l}\text { Odds Ratio } \\
\mathbf{( 9 5} \% \mathbf{C l})\end{array}$ \\
\hline Agree & $1.55(0.99-2.39)$ \\
Women know where to obtain contraception & \\
for prevention against pregnancy & \\
(RC= Disagree) & \\
Agree & $2.35^{* *}(1.19-4.65)$ \\
Women who carry condoms are promiscuous & \\
(RC= Disagree) & \\
Agree & $0.92(0.70-1.20)$ \\
It is not good for girls to know about sexual & \\
matters because they will get spoilt & \\
(RC = Disagree) & \\
Agree & $0.79(0.62-1.02)$ \\
District of study (RC = Amudat) & \\
Kaberamaido & $2.58^{* *}(1.23-5.39)$ \\
Kasese & $2.62^{* *}(1.25-5.47)$ \\
Moroto & $0.27^{* * *}(0.11-0.68)$ \\
Pader & $4.35^{* * * *}(2.15-8.79)$ \\
Tororo & $9.44^{* * * *}(4.59-19.37)$ \\
Constant & $0.03^{* * * *}(0.01-0.09)$ \\
Number of observations & 2230 \\
Likelihood Ratio Chi-squared (Probability) & $713.23(0.000)$ \\
Pseudo R-squared value & 0.279
\end{tabular}

Note: ${ }^{* *}=p<0.05 ;{ }^{* * *}=p<0.01 ;{ }^{* * *}=p<0.001$. Missing cases are not shown. Figures may not add up to $100 \%$ due to rounding errors

those who married and the unmarried as well as pay attention to the differences in level of education. This points to need for audience segmentation in designing social norm change and social behavioural change communication strategies and messages to address the heterogeneity of the population in the study sites.

Education was generally associated with supporting progressive or positive norms towards allowing adolescent girls to access contraception in the community. Other studies have also shown similar findings that formal education tends to influence attitudes and social norms positively in relation to access and use of contraceptives by adolescent girls in the communities [57-60].

Our study demonstrates that most respondents had a negative attitude towards girls' access to adolescent sexual and reproductive health (ASRH) services especially contraception. These attitudes further reinforce non supportive norms in relation to ASRH services particularly those linked to adolescent girls being allowed to access contraception in the communities that have been established by other studies [16, 23, 41].

Being in formal employment was associated with progressive norms towards adolescent girls accessing 
contraception in the community. This suggests that having a source of livelihood or being economically empowered through employment increases agency to challenge prevailing negative norms that regulate behaviour in related to access of contraception for girls.

Religion, particularly being of Christian religion was being less likely to support adolescent girls in the community to have access to contraception [61]. Some scholars have argued that religious teaching in Christian faith especially the Catholic Church tends to discourage the use of modern contraceptives because they encourage promiscuity [62]. However, the effect of education, marital status and religion fall away when all factors are controlled for in the full model.

Generally, attitudes had a strong bearing on social norms related to access to adolescent sexual and reproductive health among the study sites. Respondents who had positive beliefs towards adolescents accessing contraception were more likely to agree with the social norm that adolescent girls are allowed to access contraception in the community. Similarly, respondents who had negative or non-progressive beliefs about adolescents' access to contraception were less likely to agree that adolescent girls in the community are allowed to access contraception. This is similar to previous studies that link attitudes to social and gender norms that regulate sexual behaviour and adolescent use of contraception [63-66].

Geographical location or cultural context seemed to influence the likelihood that respondents would support a positive norm that adolescent girls are allowed to access contraception in the community. For example, the likelihood for adolescent girls to be allowed access to contraception in the community was higher in Kaberamaido, Kasese, Pader and Tororo but lower among respondents living in Moroto and Amudat all found in Karamoja sub-region - which is categorized as one of the least developed regions in Uganda [42, 43]. This implies that cultural context in the different districts plays a role in shaping social norms and attitudes related to access to contraception for adolescent girls [38, 39].

\section{Limitation}

While every effort was made to ensure representativeness, respondents who stayed at home for the entire period the survey was conducted might not be well represented. Nonetheless, the data used in this paper provides an excellent snapshot of what is happening in the community.

\section{Conclusions}

Overall, our study demonstrates that a higher proportion of respondents hold social norms that inhibit adolescent girls from accessing contraception in the community.
This is reinforced by negative attitudes towards allowing girls to access and use adolescent sexual and reproductive health services especially contraceptives. Those who believe in effectiveness of traditional methods of contraception tended to support social norms that inhibit girls from accessing contraception in their communities. Cultural context and location had an influence on supporting social norms that do not allow adolescent girls to access contraception-respondents from districts in Karamoja sub region (Moroto and Amudat) were more likely to report social norms and attitudes that inhibit adolescent girls from accessing contraception. Our findings suggest the need to apply social norm change approaches in addressing social norms and attitudes that inhibit access and use of contraception by adolescents in areas where adolescents are prone to early/unwanted pregnancies and other negative reproductive health outcomes such as sexually transmitted infections, including HIV in Uganda and other low income countries in Africa. Our findings also underscore the need for context specific ASRH programs that take into account the differences in risk factors, attitudes and social norms that affect access and use of contraception by adolescents.

\section{Abbreviations \\ ASRH: Adolescent Sexual and Reproductive Health; HP: Harmful Practices; SRHRs: Sexual and Reproductive Health Rights; UBOS: Uganda Bureau of Statistics; UN: United Nations; UNDP: United Nations Development Programme; UNICEF: United Nations Children's Fund; VAWG: Violence Against Women and Girls}

\section{Acknowledgements}

The authors wish to thank Susan Orejede Akajo (RIP) for her contribution in the process of developing the study and providing valuable comments.

\section{Authors' contributions}

PB contributed to study design, data analysis, manuscript writing and discussion. PK conducted data analysis, manuscript writing, and discussion of results. $\mathrm{MH}$ contributed to study design, review of study tools and data analysis. AN contributed to review of study tools and manuscript. EL and DB contributed to review of the manuscript. All authors have read and approved the manuscript.

\section{Authors' information}

Dr Paul Bukuluki is an Associate Professor in the School of Social Sciences, Makerere University, Uganda.

Dr Peter Kisaakye is lecturer in the School of Statistics and Planning, Makerere University, Uganda.

Dr Maxime Houinato is UN Women Country Representative.

Mr Adekemi Ndieli is Deputy UN Women County Representative.

Ms Evelyn Letiyo is Programme Specialist Ending Violence Against Women at UN Women.

Mr Dan Bazira is Planning, Monitoring and Evaluation specialist at UN Women

\section{Funding}

We acknowledge support from UN Women and Spotlight Initiative, European Union.

\section{Availability of data and materials}

The datasets used in this study are available from the corresponding author on request. 


\section{Declarations}

\section{Ethics approval and consent to participate}

All experimental protocols were approved by the Ethics committee at the School of Social Sciences at Makerere University. We obtained written informed consent from all subjects who participated in the study.

\section{Consent for publication}

Not Applicable.

\section{Competing interests}

The authors declare no conflict of interest.

\section{Author details}

${ }^{1}$ School of Social Sciences, Makerere University, Kampala, Uganda. ${ }^{2}$ School of Statistics and Planning, Makerere University, Kampala, Uganda. ${ }^{3}$ UN Women, Kampala, Uganda.

Received: 9 April 2021 Accepted: 20 September 2021

Published online: 02 October 2021

\section{References}

1. Cislaghi B, Heise L: Four avenues of normative influence: A research agenda for health promotion in low and mid-income countries. Health Psychol 2018, 37(6):562.

2. Bell DC, Cox ML:Social Norms: Do We Love Norms Too Much? J Fam Theory Rev 2015, 7(1):28-46.

3. Mackie G, Moneti F, Denny E, Shakya H: What are social norms? How are they measured? 2014

4. Nalukwago J, Crutzen R, van den Borne B, Bukuluki PM, Bufumbo L, Burke HM, Field S, Zikusooka A, Fiedler AA, Alaii J: Gender norms associated with adolescent sexual behaviours in Uganda. Int Soc Sci J 2019, 69 (231):35-48.

5. Stanford Encyclopedia of Philosophy Archive: Social Norms; 2026.

6. Cislaghi B, Heise L: Gender norms and social norms: differences, similarities and why they matter in prevention science. Sociol Health III 2020, 42 (2): 407-422.

7. Stoebenau K, Kyegombe N, Bingenheimer JB, Ddumba-Nyanzi I, Mulindwa J: Developing Experimental Vignettes to Identify Gender Norms Associated With Transactional Sex for Adolescent Girls and Young Women in Central Uganda. J Adolesc Health 2019, 64 (4):S60-S66.

8. Heywood JL: Social regularities in outdoor recreation. Leis Sci 1996, 18 (1): 23-37.

9. Morris MW, Hong Y-y, Chiu C-y, Liu Z: Normology: Integrating insights about social norms to understand cultural dynamics. Organ Behav Hum Decis Process 2015, 129:1-13.

10. Miller DT, McFarland C: When social comparison goes awry: The case of pluralistic ignorance. In: Social comparison: Contemporary theory and research. Hillsdale, NJ, US: Lawrence Erlbaum Associates, Inc; 1991: 287-313.

11. Miller DT, McFarland C: Pluralistic ignorance: When similarity is interpreted as dissimilarity. J Pers Soc Psychol 1987, 53(2):298-305.

12. Prentice DA, Miller DT: Pluralistic Ignorance and the Perpetuation of Social Norms by Unwitting Actors. In: Advances in Experimental Social Psychology. Volume 28, edn. Edited by Zanna MP: Academic Press; 1996: 161-209.

13. Institute for Reproductive Health: The Flower for Sustained Health: An integrated socio-ecological framework for normative influence and change. In. Washington DC: Georgetown University; 2017

14. Wallen KE, Romulo CL: Social norms: More details, please. Proceedings of the National Academy of Sciences 2017, 114(27):E5283-E5284.

15. Cialdini RB, Kallgren CA, Reno RR: A Focus Theory of Normative Conduct: A Theoretical Refinement and Reevaluation of the Role of Norms in Human Behavior. In: Advances in Experimental Social Psychology. Volume 24, edn. Edited by Zanna MP: Academic Press; 1991: 201-234.

16. Cislaghi $B$, Heise $L$ : Theory and practice of social norms interventions: eight common pitfalls. Globalization and Health 2018, 14(1):83.

17. Higgs S: Social norms and their influence on eating behaviours. Appetite 2015, 86:38-44.

18. World Health Organisation: Orientation Programme on Adolescent Health for Health-care Providers. 2006.

19. Pressat R: The Dictionary of Demography. Oxford: Basil Blackwell Ltd; 1985

20. Pulerwitz J, Blum R, Cislaghi B, Costenbader E, Harper C, Heise L, Kohli A, Lundgren R: Proposing a conceptual framework to address social norms that influence adolescent sexual and reproductive health. J Adolesc Health 2019, 64(4 Suppl):S7

21. Berhane Y, Worku A, Tewahido D, Fasil N, Gulema H, Tadesse AW, Abdelmenan S: Adolescent Girls' Agency Significantly Correlates With Favorable Social Norms in Ethiopia-Implications for Improving Sexual and Reproductive Health of Young Adolescents. J Adolesc Health 2019, 64(4): S52-S59.

22. Sedlander E, Rimal RN: Beyond Individual-Level Theorizing in Social Norms Research: How Collective Norms and Media Access Affect Adolescents' Use of Contraception. J Adolesc Health 2019, 64(4):S31-S36.

23. Igras S, Saldhana N, Becker-Benton A, Dagadu NA, Pirzadeh M: Scaling-up norms-focused interventions for adolescent and youth sexual and reproductive health: Current practice and reflections for moving the field forward. J Adolesc Health 2019, 64(4 Suppl):S10

24. Ninsiima AB, Leye E, Michielsen K, Kemigisha E, Nyakato VN, Coene G: "Girls Have More Challenges; They Need to Be Locked Up": A Qualitative Study of Gender Norms and the Sexuality of Young Adolescents in Uganda. International Journal of Environmental Research and Public Health 2018, 15(2).

25. Malhotra A, Amin A, Nanda P: Catalyzing gender norm change for adolescent sexual and reproductive health: investing in interventions for structural change. J Adolesc Health 2019, 64(4):S13-S15.

26. Ghimire A, Samuels F: Change and continuity in social norms and practices around marriage and education in Nepal; 2014.

27. Vaitla B, Taylor A, Van Horn J, Cislaghi B: Social Norms and Girls' Well-being: Linking Theory and Practice. In. Washington DC: Data2X; 2017.

28. Bingenheimer JB: Veering from a narrow path: the second decade of social norms research. J Adolesc Health 2019, 64(4):S1-S3.

29. De Meyer S, Jaruseviciene L, Zaborskis A, Decat P, Vega B, Cordova K, Temmerman M, Degomme O, Michielsen K: A cross-sectional study on attitudes toward gender equality, sexual behavior, positive sexual experiences, and communication about sex among sexually active and nonsexually active adolescents in Bolivia and Ecuador. Glob Health Action 2014, 7(1):24089.

30. Nalukwago J, Crutzen R, Van den Borne B, Bukuluki M, Bufumbo L, Batamwita R, Zikusooka A, Lenzi R, Thompson G, Alaii J: Adolescents discussing sexual behaviors with key influencing audiences. Glob J Health Sci 2018, 10:91-106.

31. Smith W, Turan JM, White K, Stringer KL, Helova A, Simpson T, Cockrill K: Social Norms and Stigma Regarding Unintended Pregnancy and Pregnancy Decisions: A Qualitative Study of Young Women in Alabama. Perspect Sex Reprod Health 2016, 48(2):73-81.

32. Scholly K, Katz AR, Gascoigne J, Holck PS: Using Social Norms Theory to Explain Perceptions and Sexual Health Behaviors of Undergraduate College Students: An Exploratory Study. J Am Coll Health 2005, 53(4):159-166.

33. Steinhaus M, Hinson L, Rizzo AT, Gregowski A: Measuring Social Norms Related to Child Marriage Among Adult Decision-Makers of Young Girls in Phalombe and Thyolo, Malawi. J Adolesc Health 2019, 64(4):S37-S44.

34. Svanemyr J: Adolescent pregnancy and social norms in Zambia. Culture, Health Sex 2020, 22(6):615-629.

35. Silverman JG, Decker MR, Reed E, Rothman EF, Hathaway JE, Raj A, Miller E: Social Norms and Beliefs Regarding Sexual Risk and Pregnancy Involvement among Adolescent Males Treated for Dating Violence Perpetration. J Urban Health 2006, 83(4):723-735.

36. Government of Uganda, United Nations Children's Fund: Ending child marriage and teenage pregnancy in Uganda: A formative research to guide the implementation of the national strategy on ending child marriage and teenage pregnancy in Uganda; 2015.

37. Velazquez E, Corona R, Easter R, Barinas J, Elshaer L, Halfond RW: Cultura values, mother-adolescent discussions about sex, and Latina/o adolescents' condom use attitudes and intentions. J Lat Psychol 2017, 5(3):213-226.

38. Neema S, Musisi N, Kibombo R: Adolescent Sexual and Reproductive Health inUganda: A Synthesis of Research Evidence. In. New York: Guttmacher Institute; 2004.

39. Kabagenyi A, Reid A, Ntozi J, Atuyambe L: Socio-cultural inhibitors to use of modern contraceptive techniques in rural Uganda: a qualitative study. The Pan African Medical Journal 2016, 25.

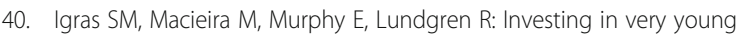
adolescents' sexual and reproductive health. Glob Public Health 2014, 9(5): 555-569.

41. Costenbader E, Cislaghi B, Clark CJ, Hinson L, Lenzi R, McCarraher DR, McLarnon-Silk C, Pulerwitz J, Shaw B, Stefanik L: Social norms measurement: 
Catching up with programs and moving the field forward. J Adolesc Health 2019, 64(4):S4-S6.

42. Byaruhanga C, Oosthuizen MC, Collins NE, Knobel D: Using participatory epidemiology to investigate management options and relative importance of tick-borne diseases amongst transhumant zebu cattle in Karamoja Region, Uganda. Prev Vet Med 2015, 122(3):287-297.

43. Wilunda C, Oyerinde K, Putoto G, Lochoro P, Dall'Oglio G, Manenti F, Segafredo G, Atzori A, Criel B, Panza A et al: Availability, utilisation and quality of maternal and neonatal health care services in Karamoja region, Uganda: a health facility-based survey. Reprod Health 2015, 12(1):30.

44. Uganda Bureau of Statistics: Natioal Population and Housing Census 2014 Main Report. In. Kampala, Uganda 2016.

45. Asiimwe BG: Household Gender and Resource Relations: Women in the Marketing Arena of Income Generating Crops in Uganda. East Afr Soc Sci Res Rev 2010, 26(2):1-30

46. de Silva RM: Ideas for Capacity Building and Educational Empowerment of Female Children in Rural Butaleja, Uganda: Applying the Central Human Capability Approach. Contemporary Rural Social Work J 2016, 8(1):1-12.

47. Uganda Bureau of Statistics: National Population and Housing Census 2014 Area Specific Profiles: Amudat District. 2017.

48. Uganda Bureau of Statistics: National Population and Housing Census 2014 Area Specific Profiles: Moroto district. 2017.

49. Uganda Bureau of Statistics: National Population and Housing Census 2014 Area Specific Profiles; Pader District. 2017.

50. Uganda Bureau of Statistics: National Population and Housing Census 2014 Area Specific Profiles: Kaberamaido District. 2017.

51. Uganda Bureau of Statistics: National Population and Housing Census 2014 Area Specific Profiles: Tororo District. 2017.

52. Uganda Bureau of Statistics: National Population and Housing Census 2014 Area Specific Profiles: Kasese District. 2017.

53. UN Women: EU-UN Spotlight Initiative and the Joint Programme to Eliminate VAWG, Harmful Practices, and Promote SRHR in Uganda: SASA! Baseline Report 2019. 2019.

54. United Nations Development Programme: Spotlight Initiative to eliminate violence against women and girls: Country Programme Document. 2018.

55. Uganda Bureau of Statistics: Sub-regions in Uganda. 2020.

56. StataCorp: Stata Statistical Software: Release 15. College Station, TX: StataCorp LLC. 2017.

57. Crossland N, Hadden WC, Vargas WE, Valadez JJ, Jeffery C: Sexual and Reproductive Health Among Ugandan Youth: 2003-04 to 2012. J Adolesc Health 2015, 57(4):393-398.

58. Rutaremwa G, Kabagenyi A: Utilization of integrated HIV and sexual and reproductive health services among women in Uganda. BMC Health Serv Res 2016, 16(1):494.

59. Odo AN, Samuel ES, Nwagu EN, Nnamani PO, Atama CS: Sexual and reproductive health services (SRHS) for adolescents in Enugu state, Nigeria: a mixed methods approach. BMC Health Serv Res 2018, 18(1):92.

60. DeBeaudrap P, Mouté C, Pasquier E, Mac-Seing M, Mukangwije PU, Beninguisse G: Disability and Access to Sexual and Reproductive Health Services in Cameroon: A Mediation Analysis of the Role of Socioeconomic Factors. International Journal of Environmental Research and Public Health 2019, 16(3).

61. Gupta N, luri da Costa L: Adolescent Fertility Behavior: Trends and Determinants in Northeastern Brazil. Int Fam Plan Perspect 1999, 25(3):125-130.

62. Andi JR, Wamala R, Ocaya B, Kabagenyi A: Modern contraceptive use among women in Uganda: An analysis of trend and patterns (1995-2011). Etude de la Population Africaine 2014, 28(2S).

63. Selikow T-A, Ahmed N, Flisher AJ, Mathews C, Mukoma W: I am not "umqwayito": A qualitative study of peer pressure and sexual risk behaviour among young adolescents in Cape Town, South Africa. Scand J Public Health 2009, 37(2_suppl):107-112.

64. MacPhail C, Campbell C: II think condoms are good but, aai, I hate those things':: condom use among adolescents and young people in a Southern African township. Soc Sci Med 2001, 52(11):1613-1627.

65. Muhanguzi FK: Gender and sexual vulnerability of young women in Africa: experiences of young girls in secondary schools in Uganda. Cult Health Sex 2011, 13(6):713-725.
66. Cislaghi B, Shakya H: Social Norms and Adolescents' Sexual Health: An introduction for practitioners working in Low and Mid-income African countries. Afr J Reprod Health 2018, 22(1):38-46.

\section{Publisher's Note}

Springer Nature remains neutral with regard to jurisdictional claims in published maps and institutional affiliations.
Ready to submit your research? Choose BMC and benefit from:

- fast, convenient online submission

- thorough peer review by experienced researchers in your field

- rapid publication on acceptance

- support for research data, including large and complex data types

- gold Open Access which fosters wider collaboration and increased citations

- maximum visibility for your research: over $100 \mathrm{M}$ website views per year

At BMC, research is always in progress.

Learn more biomedcentral.com/submissions 